\title{
Implementing a Child Protection Curriculum: Lessons from a South Australian Trial
}

\author{
Bruce Johnson \\ University of South Australia, Australia
}

\begin{abstract}
In 2004-5, the South Australian Department of Education and Children's Services (DECS) revised its child protection curriculum by producing new draft materials and having them trialled by teachers in a small number of schools. The trial was conducted to establish the quality of the draft curriculum and to identify the support processes used by schools to help teachers implement the new curriculum. The study confirmed that the curriculum materials were of good quality and generally helpful to teachers planning to teach child protection. It also revealed that school leaders and teachers used a range of sophisticated micropolitical strategies to address several key issues and dilemmas that emerged from the trial. These strategies included establishing the moral purpose of the child protection curriculum, reducing teacher isolation by building collaborative coalitions, integrating the curriculum with other school initiatives, and dealing with resistance to the curriculum. Knowledge gained from the study will inform other schools wishing to use the materials (launched this year as Keeping Safe (DECS, 2008)) to support the teaching of child protection strategies.
\end{abstract}

\section{Introduction}

The South Australian Department of Education and Children's Services (DECS) strongly endorses the view that the prevention of child maltreatment is a moral, social and professional responsibility of the education system, its constituent schools and centres, and its employees (Department of Education, Training and Employment, 1998).

In response to submissions made by DECS, the Layton Review into Child Protection in South Australia (Layton, 2003) recommended that personal safety programs in DECS schools and preschools be updated. The rationale behind the 
recommendation was that schools should teach children and adolescents about personal safety and to provide them with the knowledge and skills to manage their own safety.

Consistent with its commitment to child protection and in response to the Layton Review, DECS initiated the Child Protection Curriculum Materials Development and Trial in mid 2004. It also committed itself to integrate these efforts into the National Safe Schools Framework that addresses bullying, harassment, violence and child abuse and neglect.

The trial of newly developed child protection curriculum materials took place in a cluster of schools in the southern region of Adelaide and involved one secondary school, four primary schools, and four kindergartens. A total of 26 classroom teachers trialled the curriculum materials over 10-14 weeks in terms three and four, 2004. Teachers were supported in their efforts by school leaders, school counsellors, and the DECS project officers and writers who produced the draft curriculum materials.

DECS also sought to find out what difficulties were experienced by teachers and school leaders involved with teaching personal safety. In commissioning a study of the trial and the implementation of its Child Protection Curriculum Materials, DECS recognised that testing and implementing new personal safety curricula can be a difficult and problematic process that requires local support and decision making. In undertaking this work, DECS explicitly rejected a fidelity orientation to curriculum implementation based on what Michael Fullan called 'faulty assumptions and ways of thinking' about how changes can be 'installed' in schools (Fullan \& Stiegelbauer, 1991). As a consequence, DECS rejected the view that program implementation is simply a matter of replicating the same ideas and approaches, in a technical and mechanistic way, in classrooms across the entire education system.

DECS wished to showcase the implementation work of one group of schools and preschools to demonstrate what is involved in local level child protection innovation and change. Through the development of this study, it is hoped that other schools and groups of schools will undertake similar projects with a greater understanding of the kinds of difficulties they will face as they seek to change practices at a local level.

\section{Background}

The main goal of primary and secondary prevention programs is to stop child maltreatment from occurring in the first place, rather than counterattacking after the damage has been done. Primary prevention, in particular, is an attractive option because it is 'more sensible, humane, pragmatic, and cost effective' than to struggle, however valiantly and compassionately, with the consequences of abuse (Cowen, 1983: 14).

Due to the close and ongoing contact children have with schools during periods when they are statistically at high risk of being abused, schools are ideal 
sites for the delivery of child protection programs. An estimated 400-500 school based programs were developed in the US during the early to mid 1980s. Subsequently, all Australian state ministries or departments of education either adopted an American program or developed local programs. The single most widely adopted program in Australia was Protective Behaviours. In South Australia, over 8,000 teachers were trained to teach the program between 1985 and 1992.

In the mid 1990s, DECS commissioned the largest and most comprehensive evaluation of a child protection program ever made in Australia: the Review of Protective Behaviours in South Australia (Johnson, 1995). Nearly 1,000 teachers were surveyed about how they used the program and what affected its use. The review (Johnson, 1995: 72) made several recommendations to promote the teaching of child protection curricula in South Australian schools:

- more detailed curriculum materials: 'The development of a range of materials would address several of the issues of contention raised by teachers who were selective users of the program. For example, they could provide practical examples of approaches that alleviate concerns about the age appropriateness of sections of the program. Also, they could ease teachers' concerns about the lack of clarity of the program. Curriculum support materials will not, however, solve all implementation difficulties - the experience of decades of expensive centralised curriculum development testifies to this.'

- more school level implementation support: 'Teachers need support at the local level as they grapple with the day to day difficulties associated with doing something new and challenging. Teachers readily identified the provision of school level implementation support as an important ingredient in the implementation equation.'

- balancing support and pressure: 'By participating in negotiations about the implications of accepting the over-riding rationale for personal safety education, teachers will be under pressure from their peers to utilise a range of support mechanisms to address their teaching in the area.'

- increasing parent and community support: 'local action by schools to inform parents about issues of personal safety can effectively mobilise support for school based prevention ... By linking school personal safety programs to the wider movement to help prevent abuse, parent and community education can reduce the gap ... between program goals and community expectations.'

While the Review of Protective Behaviours raised numerous questions about how child protection is taught in our schools, little further work was undertaken to enable schools to 'provide ongoing child protection and abuse prevention programs' (DETE, 1998: 4). The department's child protection focus was more on other policy outcomes, for example, establishing mandatory reporting systems, than on promoting the teaching of child protection programs to all children. 
By late 2001, however, senior departmental officers had become concerned about the lack of monitoring within schools, districts and the education system as a whole of how this key feature of DETE's child protection policy was being implemented. As a consequence, the Child Protection Risk Management Committee was established in 2002 to review the department's responsibilities within its 1998 policy framework. It concluded that the provision of personal safety education by schools was one area of the policy that needed greater support.

Public concern over children's safety was growing at the same time because of revelations of systematic and long-standing child sexual abuse, particularly in church settings, involving priests, child-care workers, sports coaches, youth workers, and teachers. The political reaction to this growing concern was immediate. The newly elected Labor government in South Australia announced that lawyer Robyn Layton would review South Australia's child protection provisions. The new Minister for Education also announced a ten-point plan for safer schools.

In response to these bureaucratic and political concerns over schools' child protection roles, the department appointed a curriculum child protection project officer to consult with schools to inform the department's submissions to the Layton Review. Those submissions contained references to the need to review child protection curricula that were subsequently endorsed in the Layton Review's recommendations for action (Layton, 2003). In late 2003, the Minister for Education accepted this recommendation and announced a review of child protection curricula in South Australian schools.

During early 2004, a team of writers with expertise in child protection curricula was assembled to develop the first draft of the new curriculum materials. Five documents were written for the different bands of the South Australian Curriculum Standards and Accountability (SACSA) Framework-Preschool, Reception-Year 2, Primary-Years 3-5, Middle-Years 6-9, Senior-Years 1012. The materials contained learning and assessment activities related to several key learning areas of the SACSA: health and physical education, English, and studies of society and the environment. The draft materials were distributed to various committees within DECS for comment and feedback. A second draft of the materials was produced in mid 2004 to be used in an intensive school trial.

\section{The trial}

\section{Purpose}

The second draft of the child protection curriculum was trialled as part of a rigorous evaluation program that aimed to:

- produce updated curriculum materials that use engaging methodologies and current popular cultural resources

- develop materials that can be adapted for diverse learners, including those from Indigenous groups and students with disabilities 
- design assessment activities that are consistent with the South Australian Curriculum Standards and Accountability framework

- investigate the most effective means of supporting teachers to implement these changes in their schools and classrooms.

\section{Scope and scale}

The trial was deliberately limited in scope and scale to one network of schools in Adelaide's southern suburbs. The nine preschools and schools which participated are geographically concentrated, serve a largely socially and economically disadvantaged community, and apart from the secondary school, are small to medium in size (50-250 students). The schools also had a strong and positive history of working collaboratively on other projects, their leaders knew and respected each other, and importantly, key personnel in the cluster had expertise in child protection. The trial sought to capitalise on the advantages of networked learning approaches to school innovation and change (National College for School Leadership, 2003).

\section{Time}

The trial was conducted over a relatively short time due to political pressures to produce the new curriculum as soon after the release of the Layton Review recommendation as possible. The trial schools were selected late in the second term of 2004, and participating teachers began trialling the materials in their classrooms in the third week of term three. In the preschools and primary schools, the trial concluded after 10 weeks classroom work in week three, term four, 2004. In the secondary school, the trial continued until week eight, as exploring the diversity of avenues for teaching the program required further time.

\section{Systems support}

The schools that participated were provided with all draft curriculum documents and the support of two centrally appointed child protection project officers. These project officers organised a full day of training for participating teachers, provided information and advice to teachers on the structure and content of the new curriculum, gave practical advice on how to use the curriculum materials in classrooms, collated feedback from teachers and liaised with a professional writer who was engaged to redesign the materials.

DECS allocated $\$ 60,000$ to the cluster for the trial. The schools decided to spend most of this on teacher release for training and development and for collaborative planning within and across schools.

\section{Management}

The project was managed locally by a committee of school leaders and coordinators from the schools, central office project officers, and a superintendent who was responsible for the project. This group not only managed the project budget and timeline, but also debated many of the educational and policy issues that were raised 
during the trial; it functioned as a forum for the discussion of controversial and sensitive issues like principals' curriculum authority and questions of teacher compliance with curriculum policy, how to deal with media and political interest in the trial, how and when to inform and involve parents and how to work with interagency groups. Some of these debates are reported in more detail later in this paper.

\section{Political sensitivities}

The project management committee and DECS child protection personnel were very cautious about media and political involvement in the trial following the negative criticism of trial sex education materials during 2003 (see Johnson, 2007). It was decided not to release copies of the draft materials to the media or to interest groups, including sitting members of parliament. Instead, two briefings with members of parliament were held to explain the Child Protection Curriculum trial and the project superintendent dealt with media enquiries.

\section{Researching the process}

DECS wished to document how teachers and school leaders dealt with teaching a new child protection curriculum. The chequered history of the Protective Behaviours Program, together with an intensified interest in child protection by the media, state politicians and the public meant that the trial and its outcomes would receive greater scrutiny than in the past. As a consequence, I was approached to submit a research plan to address the following questions:

- What are the key dilemmas and tensions involved in trialling and implementing new approaches to teaching personal safety?

- What features of the new personal safety curriculum materials promote the teaching of key personal safety concepts and skills?

- What positive micropolitical strategies do school and cluster leadership teams use to promote the teaching of key personal safety concepts and skills?

DECS accepted my proposal to study the trial using participant observation and interview methods to collect data.

As a participant observer in the trial I reviewed the new materials, attended all management meetings, took part in professional development activities with teachers and school leaders, and contributed to parliamentary briefings. During these sessions I had informal discussions with many people about what they were doing and why, what they were planning to do, what difficulties they had experienced, what help they had received to address them, and what had been successful. I also collected resource materials, minutes of meetings and other support papers developed by the project officers to explain the history of the project and the purposes of the trial. Finally, towards the end of the trial period, I formally interviewed all school personnel involved in the trial. This involved 13 interviews conducted in small focus groups using a semi-structured protocol. Classroom 
teachers and school leaders were interviewed in separate groups. All interviews were audio taped and transcribed.

I analysed the data to identify the key issues, dilemmas and tensions that arose during the trial and how they were addressed by teachers, school leaders and DECS project officers. The insights gained form the basis of this paper.

\section{Results}

\section{The curriculum materials}

Almost all the schools involved agreed that good quality curriculum materials are essential for planning and teaching personal safety knowledge, concepts and strategies. Teachers were generally positive about the draft materials they trialled. They willingly provided feedback to DECS project officers about the format of the materials, the suitability of the curriculum content for the age group they taught, the usefulness of the suggested activities, the availability and relevance of resource materials cited in the curriculum, other sources of resources and up to date audiovisual materials, and the development of more relevant scenarios for discussion.

They gave this feedback in their Child Protection Curriculum Feedback Journal, a 40 page booklet prepared by the DECS project officers. They also commented during interviews on the explicitness of the materials, the level of detail provided, and the suggestions made to integrate the child protection content into other learning areas like growth and development, and studies of society and the environment. One school leader summarised his views on the draft materials:

The majority of the program is exactly what teachers will have been doing but it's in a different framework. Just like the drug strategy really. The pointy end is better. There's a whole lot more sources about strategies, good teaching strategies to use. It's really gutsy stuff; it's very interesting to the kids and teachers who are socially aware or able to develop cohesive classrooms. They will love it because of the way it's presented. I think it's presented pretty well. And I think that will be true for secondary kids as well. They will enjoy working on those subjects. Certainly, that's been the response of our kids. They've enjoyed doing the work in those areas. So I don't think it's something to be afraid of at all. And I reckon it's a hell of a lot better than Protective Behaviours. And there are specific suggestions about how to teach it too, which is what wasn't in PB.

(primary school leader)

Several teachers commented that the curriculum materials helped them deal with the 'tough' or 'sensitive' areas of the curriculum that covered naming body parts, wanted and unwanted touching, and identifying and reporting abuse.

I looked at the draft materials and worked out where I thought I needed to fill a gap in what I usually teach. My aim was to get to the tough stuff because that's what I hadn't done before. I'd always, really, I suppose, stopped short of getting on to things like naming body parts. And while it had been done in family life stuff and sex education it had never been specifically done as part of protective behaviours or child protection. So my aim was to do enough of the other stuff to ensure that we could move on to that. And in actual fact, we did get there and touch on some of the more 
difficult things like what is abuse and reporting abuse and the naming of body parts. And the kids just received it. They just took it as being a natural progression.

(primary school teacher)

This point was repeated by quite a few teachers who saw good quality teaching materials as essential for supporting teachers who may be reluctant to teach parts of the curriculum.

T1: I think a part of the support needs to be in the materials because it is such a sensitive area for teachers, and a lot of people shy away from it.

T2: Yes, they find it too hard. The easier it is for teachers to teach, or even to look at the area, the more people are going to teach it, I think.

T1: Because the materials are user friendly, and the less things they have to prepare or organise in their own time, the more likely they are going to be able to use it.

(primary school teachers)

Other teachers commented on the suggested teaching approaches that modelled the 'one step removed' strategy. They saw the strategy as a safe way to raise matters that would normally be too personal to discuss in the classroom.

But I found the scenarios, where you actually set up a situation in a classroom and you say, like for international students, okay imagine that you had a friend and this happened to your friend and you go through all the detail. We had about ten different scenarios like that. So you're not actually making the students the object of the focus, you're asking them to discuss together, if you had a friend in that situation what would be the advice you would give them and what should they do and how should they cope? They're not actually being asked in any way to share out of their own personal situations. And hopefully out of the discussion if there are kids that are having problems they actually benefit from hearing other people discuss possible outcomes without it being personally targeted.

(secondary school teacher)

One issue that caused dissent was the level of explicitness of the curriculum materials. The developers of the curriculum opted for a high level of explicitness in response to advice from child protection experts that even quite young children need a common vocabulary to describe parts of their bodies. This position is consistent with other curriculum areas like health and physical education which suggest the use of explicit and anatomically correct terms when teaching about human sexuality.

Views on this issue were most polarised at the preschool level. One group of teachers was quite clear about the need for explicitness:

T1: Well I personally thought that if we are going to be promoting this curriculum and teaching the children how to be able to protect themselves that one thing they needed to know was the appropriate names of body parts.

T2: Well I personally think that four year old children, the nature of their age makes them particularly vulnerable to abuse and therefore they need access to explicit language to be able to report it, to have those strategies. And I think that we both feel fairly confident doing explicit teaching as it is a normal part of our repertoire.

(preschool teachers at the same preschool) 
Another group of pre-school teachers disagreed.

We were very concerned about approaching the abuse side of things and safe and unsafe touching. Although that wasn't so bad, it was talking about the private parts more than anything. We had to sort of test each other out a bit to get used to using that language with four year olds. We just sort of felt, well hang on, we're not used to this ourselves. And having to do it, bang, without having the time to really just do it gently or gradually and get ourselves used to it gradually, we just thought that was a bit unfair.

(preschool teacher at another preschool)

These fundamental differences between the views of teachers have implications for policy makers and school leaders. They raise important questions about curriculum authority and the discretionary powers of teachers to selectively teach or omit sections of the child protection curriculum. These are discussed in the next section of this paper under the heading 'Delineating curriculum authority'.

In summary, the trial produced very practical and detailed information about the curriculum. This information informed the design of subsequent drafts of the materials which were disseminated more broadly to selected schools in 2005 , culminating in the release of the final curriculum, Keeping Safe, in January 2008 (DECS, 2008). However, the curriculum materials were almost a minor distraction from more fundamental issues confronting teachers and school leaders during the trial period. These are discussed in the following sections of the paper.

\section{Delineating curriculum authority}

School leaders and teachers struggled to resolve the dilemma over who has or should have the authority to decide how personal safety is taught in their schools. Views differed widely on this issue. Many teachers saw the move to mandate the teaching of personal safety curricula as a bureaucratic knee-jerk reaction to political and media pressure on schools to do something about child abuse. These teachers and school leaders argued that:

- the content of the curriculum is too 'intimidating and daunting' to expect all teachers to teach it

- some teachers lack the sensitivity and interpersonal skills to teach it

- some teachers have difficulty dealing with personal safety issues because of a past history of abuse

- schools lack the surveillance mechanisms to ensure classroom teachers comply with policy directives

- mandating the curriculum would insult teachers and lead to the withdrawal of their goodwill and commitment to student safety- 'And the teachers would become very political. You want me to do it? Make me! To mandate it would kill it' (secondary teacher)

- mandating the curriculum would send contradictory messages to teachers, children and parents as it could be construed as professional bullying'Mandating is just a bullying way of trying to solve a problem. It would 
be ironic implementing a personal safety program using bullying tactics' (primary teacher)

- some aspects of teaching are beyond mandates-'How can developing rapport or trust or positive relationships with kids be mandated? (preschool teacher).

Other teachers and school leaders were less forgiving of their colleagues who paid lip service to teaching personal safety but who, in reality, avoided teaching critical aspects of the curriculum. They supported systems endorsed, non-negotiable expectations of teaching the child protection curriculum: 'We are strong about saying, we are upfront in saying it's non-negotiable, yep and you need to teach this' (primary school leader). These educators argued that:

- an unambiguous and 'strong mandate should be issued by the chief executive and from the minister' (primary school leader)

- teaching the curriculum was a professional responsibility that individual teachers could not avoid

- if teachers were sensitive about teaching aspects of the program, then they should admit this and seek the assistance of their colleagues and school leaders

- teachers should receive support and training to use the new materials

- teachers should have access to resources to complement the curriculum materials.

These educators endorsed the view popularised by Michael Fullan that teachers frequently need a mixture of support (professional development, quality resources, and helpful colleagues) and pressure (clearly stated and reinforced expectations) to improve their programs. 'My initial reaction is that it's good to mandate it, AND to have training and the support' (primary school teacher).

Both pressure and support are necessary for success. We usually think of pressure as a bad thing, and support as good. But there is a positive role for pressure in change. There are many forces maintaining the status quo. During the change process, interaction among implementers serves to integrate both pressure and support ... Pressure without support leads to resistance and alienation; support without pressure leads to drift or waste of resources.

(Fullan \& Stiegelbauer, 1991: 91)

For these educators, the delineation of curriculum authority was clear. Without alienating their colleagues or provoking defensive reactions, these teachers and school leaders clearly articulated the view that teachers have a collective professional responsibility to teach core elements of the child protection curriculum and that individual teachers do not have the discretionary power to selectively omit these elements. They established the moral purpose of the curriculum trial and skilfully applied a number of micropolitical strategies to support its implementation by teachers. 


\section{Using micropolitical strategies}

School leaders and teachers in the trial schools used positive micropolitical strategies that promoted the collaborative resolution of problems with teaching the child protection curriculum. According to Blasé:

[m]icropolitics refers to the use of formal and informal power by individuals and groups to achieve their goals in organizations.

In large part, political actions result from perceived differences between individuals and groups, coupled with the motivation to use power to influence and or protect ... Both cooperative and conflictive actions and processes are of the realm of micropolitics.

(Blase, 1991: 11)

In the discussion that follows, four micropolitical strategies used by school leadership teams are identified:

1. establishing moral purpose - how school leaders and teachers used values to define and defend the rationale for the draft curriculum

2. reducing teacher isolation and building collaborative coalitions-how school leaders and teachers used teams and mentors to support teachers

3. integrating the trial with current school priorities-how school leaders and teachers made links to other school initiatives

4. dealing with resistance-how school leaders and teachers identified different forms of resistance, what they thought caused it, and what strategies and tactics they suggested to deal with it.

\section{Establishing moral purpose}

Interestingly, in an era of moral uncertainty, school leaders and teachers in all but one of the schools invoked moral arguments embedded in conceptions of "what is good for children and adolescents' to justify investing time and energy in the trial. For example, most educators justified the involvement of their school by pointing out their students' need to learn about personal safety. One cited the threats to safety posed by a nearby shopping complex which had a problem with teenage gangs. Another mentioned newly arrived international students as a particularly vulnerable group that needed explicit information about keeping safe. A secondary teacher cited work experience in unsafe environments as a threat to the well being of Year 10 students. Yet another school leader recounted her dismay at discovering that a class of children at a school she had previously taught at had been systematically abused by a teacher but did not know how to tell anyone about it.

Telling these stories was an important means of sharing deeply felt beliefs about children's vulnerability and the role of schools in teaching children about personal safety. As Quong et al. (1999: 442) suggested, 
we store our life experiences, values and beliefs in the form of stories, not in detached lists of facts and figures ... stories reflect an individual's beliefs, at a specific point in time, about the contexts within which they work.

(Quong et al., 1999: 442)

As was the case in another school reform project (Johnson, 2004), appealing to teachers' sense of moral purpose and articulating almost non-contestable (at least publicly) views on the primacy of student safety was a significant micropolitical strategy employed by the sponsors of the curriculum trial in most of the schools. As one leader explained, establishing a 'bottom line ... everything else is not going to be important if they can't protect themselves'-provided a non-negotiable rationale for the new curriculum.

While many teachers promoted this rationale and generally accepted responsibility for teaching about child protection, there was a sense that teaching the new curriculum should not be seen as the only means of protecting children. One leader in particular worried about the misplaced confidence some policy makers had in the capacity of a new set of curriculum documents to 'solve the problem of child abuse'. She said:

I get very concerned whenever I hear the radio or read a newspaper article that some minister or some person says that a program at school will do it. While we develop school curricula to look at child protection issues, if we don't have support through the health systems, through the media and through parent groups and other agencies, I think it won't be as successful as it should be.

We've had meetings with parents and we've talked about the role of schools to tell parents about child protection but it's not a matter of just telling parents what we're doing, it's a matter of changing beliefs in our society these days. Now perhaps the time is right for this to happen, but our curriculum will not stand on its own to help children. We're not that powerful. No, we're not. (primary school leader)

While asserting that schools and teachers can make a difference, she pointed out the dangers associated with over-claiming the influence of school based prevention efforts. Her statement is a warning to child protection advocates that over-investing in single prevention strategies can weaken the justification and rationale of other initiatives intended to counter child maltreatment.

\section{Reducing teacher isolation and building collaborative coalitions}

By far the most common and powerful support strategy used during the trial was 'teaming' - the deliberate establishment and encouragement of collaborative pairs or groups of teachers who worked together on the trial. These teams reduced teachers' isolation and sense of vulnerability by providing them with the practical and emotional support needed to tackle sometimes sensitive and difficult teaching tasks. As one primary school leader said:

The response from a lot of teachers in the project has been, working together has been a really good way of doing it. Certainly, that's what my crew have said. We wouldn't have got anywhere near where we did without that team solidarity and collaborative support, and the planning time. So it was about the training and the collaboration. It's not really so much about the training I don't think because the program's not that hard. It's more about the collegial support around, and the school structures I think. 
(primary school leader)

Teachers from the same school were similarly convinced that their team approach was instrumental in providing the timely support they needed to undertake the trial.

T1: Certainly, it's been good for us working as a team. If you just got the materials dumped on you as a folder in the classroom, and you had to just teach them, it would not be very effective.

T2: You should insist that the school allows you to get together like we've been able to, to thrash out how we're going to do it, what we are going to do.

T3: The training and support, and time have just been huge.

(primary school teachers)

These teachers, however, identified what is needed for forming successful teams-having the time to meet, discuss, debrief, grizzle, make plans, share resources, and generally support each other. In kindergartens and primary schools in particular, where teachers have many contact hours with their classes, buying the time to release them is expensive. As one school leader said, having a little extra funding to facilitate teacher collegiality would bring huge benefits:

The best way to support us would be by providing some money through the global budget for child protection that would enable us to have TRT support to release skilled teachers in the school to support their colleagues. If we had that, we could then restructure and cover most of the areas over a two year period properly. No, three years probably. If that was a commitment, like the leadership allocation is, and it wouldn't need to be a lot, we could then aggregate that time and put it into TRTs to get teachers together more.

(primary school leader)

While the schools that participated in the trial received small amounts of money to release teachers, this principal was making a more general point about the need to resource teacher release for extended periods of time (2-3 years) if significant collegial learning is to take place.

There were other forms of team building in several schools that were based on pre-existing relationships and commitments to work collaboratively. Teachers spoke of making 'professional and personal pacts' with colleagues to offer 'total support', of 'being on the same wave length' and of 'sharing unique insights together'. These bonds were strongest in two kindergartens where teachers taught in close proximity to each other. They were a strong source of reassurance:

We made professional and personal pacts that we were going to understand and support one another if we felt uncomfortable. And I did say to Barb, I feel uncomfortable teaching this particular activity. But I knew I had Barb or Helen's total support and that they would be in close to where I was teaching if I needed their support - they would jump straight in. I know that if I stumbled on a few words I would feel really comfortable. I don't think many other sites have that unique relationship where you can say 'I need your support today'.

(kindergarten teacher, pseudonyms used) 
Other teachers sought assistance from colleagues even though they didn't have a formal arrangement in place defining their relationship - they simply asked for help. One teacher in particular had concerns over teaching aspects of the program due to her personal experience. She reported that:

I had a few concerns and worries on a personal level. I've experienced a lot of the things we talk to the kids about in there personally, and I found it very difficult to do this on my own. And so Rod [another teacher] actually did it with me. So a suggestion I would make is that if you have any kind of doubts at all, that you teach with someone else. Then you can leave the room if it becomes too sensitive for you.

(primary school teacher, pseudonym used)

Teachers' and school leaders' reports of positive collegiality confirm the importance of providing structures and opportunities that break down isolationism and promote connectedness between teachers (Hargreaves, 1994).

\section{Integrating the trial with current school priorities}

Several schools made explicit links between existing school priorities and the aims and rationale of the child protection curriculum. By pointing out the high degree of congruence between what is already being done and what is proposed to be done, school leaders sought to normalise the child protection initiative and counter claims that it was yet another thing to be added to an already crowded curriculum.

Now if we look at the school's philosophical statement and the values sitting up on the wall, it's a matter of saying, if we're on about promoting this type of school and we value these types of things, what does that mean we need to do? So things like the child protection stuff then become one of the key ways to say, well, if we use this sort of stuff we are promoting what we value.

(secondary school leader)

This ability to reframe the new curriculum within existing values and priorities was important for convincing teachers that they had the space in their busy schedules to teach personal safety.

Several senior staff made the point that curriculum leadership is vital for identifying new ways to incorporate personal safety into an already crowded curriculum. Their approach was to use the new materials to strengthen teaching personal safety in already existing programs, rather than to timetable personal safety as a new and discrete subject taught by experts in child protection.

\section{Dealing with resistance}

Teachers involved in the trial were hand picked by their leaders because they were excellent operators, were interested and experienced in teaching child protection, and were teaching the year levels required by the sponsoring authority. As a consequence, there was little overt resistance to the implementation of the trial curriculum among these teachers.

Yet school leaders commonly talked about compliance with system and school policy and teacher resistance to initiatives to change practices in the child 
protection area as they represent an ongoing leadership challenge. Leaders spoke about teachers who were reluctant to change their curriculum and pedagogic practices and those who made excuses for not teaching child protection. Common excuses were:

- we haven't got all the resources

- I haven't got time to teach this_-what do I leave out to fit this in?

- it's too hard

- my kids won't cope with the explicit stuff

- I haven't got the knowledge or skills to teach this

- it's all a political beat-up anyway

- teaching this stuff isn't part of my job

- it doesn't work

- specialists like counsellors should deal with this, not classroom teachers like me.

Interestingly, however, none of the school leaders were disrespectful of teachers who made these excuses; they spoke of trying to understand their points of view and of working with them to work through any problems they had. They spoke at length about how they would support these teachers.

I would listen to what their objections are and clarify what they are and provide information about those objections really. Work through the process, find out what the tensions are, and find out what we need to do. Take the heat off in the first instance.

'We don't need to do this straight away, let's work on it. Let's work on the parts that we can do and you are comfortable with. What is it that you're not comfortable with? Which parts?'

Because it's very rare that someone will say the whole thing sucks. Particularly the way the program is. So there's likely to be a reason why it is difficult for people to do. So it's working around that and it's working around it with strategies. So the bottom line is, I'm not going to force teachers to teach those bits but we are going to do it as a school somehow. So we'll be working as a team and that's the way to take the heat off I think.

(primary school leader)

This short analysis of the micropolitical strategies used by school leaders during the trial shows the importance of this local level work and the need for leaders to be skilled in and knowledgeable of micropolitics. It also shows that local initiative is indeed a powerful force in the curriculum change equation, thus challenging the faulty assumption that such changes can be relatively easily installed in schools by providing quality curriculum materials.

\section{Dealing with increased anxiety over children's safety}

Participants in the trial were well aware of the social and political context in which they lived and worked. Reports of the attempted abduction of two adolescent girls in 
a nearby suburb during the trial period highlighted increased community concern over children's safety. So too did the resignation of the Anglican Archbishop of Adelaide over his handling of child abuse claims within the Adelaide diocese in June 2004. Teachers referred to these and other incidents to justify an increased commitment to school based child protection education. In fact, many teachers felt more confident of community support for their efforts than they did during the late 1980s when they attempted to teach the Protective Behaviour program.

Other teachers were more circumspect about the consequences of heightened media led concern over children's safety. One school leader described the public reaction as 'over the top' and 'ill directed' at the wrong people. Another teacher spoke of the need to use caution when using recent publicity about allegations of child abuse to justify the child protection curriculum. He believed that 'catastrophising' and 'sensationalising' child safety merely contributed to a growing 'public panic' about an ever expanding list of 'threats' to children's wellbeing (primary school teacher). The consequences of this 'panic' were increased suspicion of male teachers as potential child abusers, increased surveillance of teachers by parents and school leaders, loss of independence by children who were 'oversupervised' by parents and teachers and increased 'risk-anxiety' among parents, teachers and school leaders. He urged schools to be cautious and careful when dealing with parents who may be caught-up in this 'near hysteria'.

Against this backdrop of increasing public concern over children's safety, other school leaders and teachers spoke about ways to better inform parents and the community about child protection and to increase their support of school based prevention efforts. Several schools ran parent information sessions but reported low attendances. Others sent home information letters endorsed by their governing councils. Another school permitted several concerned parents to participate in classroom activities with their children (although this was roundly criticised by other network members as a breach of children's privacy). Finally, nearly all kindergarten teachers reported involving parents in discussions about the new curriculum and what they were teaching.

Parental reaction to the trial was mostly positive. The most common parental concerns were about:

- their children getting the wrong idea about touching

- children being given ammunition to make false allegations against parents

- giving children the wrong idea about their rights

- scaring children with stories of abuse.

School leaders and teachers often dealt with these parental concerns as they were raised.

In summary, raised public and parental awareness of child abuse and neglect was seen as a double-edged sword by many of the participants in the trial. Increased support for the child protection curriculum was one consequence of this. A less 
favourable consequence was growing parental fear and overreaction to perceived threats to their children's safety. Despite this ambivalence, most schools accepted that parental support for their efforts was necessary and instituted processes to inform parents and to allay their fears and concerns.

\section{Conclusion}

This study looked at how a small network of schools accepted and met the challenges associated with trialling a new child protection curriculum. It found that teaching child protection is difficult and requires a clearly articulated rationale and skilled local micropolitical intervention to resolve many of the dilemmas and tensions experienced by teachers. The following conclusions can be drawn from the study.

\section{The curriculum materials}

- The draft curriculum materials were seen by most teachers as relevant and helpful when planning child protection learning activities.

- Most teachers supported the highly explicit nature of the materials; a small minority of teachers at the preschool level did not.

- The detailed feedback and additional resources, ideas and scenarios provided by teachers were useful for revising and improving the materials.

- Most teachers and school leaders believed that quality curriculum materials are a necessary but not sufficient requirement to ensure quality teaching. Considerable local level support is also needed.

\section{Delineating curriculum authority}

- School leaders and teachers faced a dilemma over whether sections of the draft curriculum should be mandated.

- Most school leaders and teachers opposed the bureaucratic application of curriculum authority through mandates, but supported the articulation of a clear expectation that teachers have a collective responsibility to teach core components of the curriculum.

- Using managerialist mandates alone was considered by most participants in the trial to be a naive and flawed approach to policy implementation; attention to local level support was considered more crucial.

\section{Using micropolitical strategies}

- Most school leaders were committed to working with teachers in collaborative and supportive ways to resolve any issues associated with using the draft materials. 
- Key personnel in the schools and network articulated strong moral arguments justifying teaching the curriculum in the interests of the children.

- The most common means of supporting teachers was to form collaborative teams.

- School leaders skilfully positioned the child protection curriculum alongside other school priorities so that teachers could make links between them. This was especially relevant at the secondary level as elements of the curriculum were taught across five to six program areas.

- School leaders actively sought to understand and address the underlying bases of teacher resistance to the program, rather than being critical or dismissive of it.

\section{Understanding the social and political context}

- Teachers and school leaders understood the external contextual factors that impinge on debates about child protection and took these into account when interacting with parents.

- Teachers and school leaders saw heightened community concern over child abuse as strengthening the underlying rationale for child protection education. However, some teachers also acknowledged the destabilising influence of unwarranted public panic over children's safety.

\section{References}

Blase J, 1991, 'The micropolitical perspective'. In Blase J, (ed.), The politics of life in schools. Sage Publications, Newbury Park, 1-18.

Cowen E, 1983, 'Primary Prevention in Mental Health: Past, Present and Future'. In Felner R, Preventive Psychology: Theory, Research and Practice. Pergamon Press, New York.

Department of Education, Training and Employment (DETE), 1998. 'Child Protection Policy'. Circular and policy dated 29th December, 1998.

DECS, 2008, 'New child protection curriculum rolled out'. Media release <www.ministers.sa.gov.au/news.php?id=2708> viewed July 2008.

Fullan M and Stiegelbauer S, 1991, The New Meaning of Educational Change. Teachers College Press, New York.

Hargreaves A, 1994, Changing Teachers, Changing Times: Teachers' Work and Culture in the Postmodern Age. Cassell, London. 
Johnson B, 1995, Teaching and Learning about Personal Safety: Report of the Review of Protective Behaviours in South Australia. Painters Prints, Adelaide.

Johnson B, 2004, 'Local school micropolitical agency: an antidote to new managerialism'. School Leadership and Management, 24( 4), 267-286.

Johnson B, 2007, "The orchestration of a "moral panic" over sex education: a South Australian case study'. Postgraduate seminar presented at the Faculty of Education, University of Cambridge, 24th September, 2007.

Layton R, 2003, Child Protection Review Report: Our Best Investment: A State Plan to Protect and Advance the Interests of Children. Government of South Australia, Adelaide.

National College for School Leadership, 2003, 'What are we learning about? Establishing a network of schools'. Networked Learning Communities, National College for School Leadership, Cranfield, UK <www.nscl.org.uk> viewed April 2005.

Quong T, Walker A \& Bodycott P, 1999, 'Exploring and Interpreting Leadership Stories'. School Leadership \& Management, 19(4), 441-53. 